\title{
Hipertensi pada Perempuan di Wilayah Kerja Puskesmas Brabasan Kabupaten Mesuji Tahun 2019
}

\author{
Hypertension in Women in the Work Area of the Brabasan Health \\ Center, Mesuji Regency in 2019
}

\author{
Yuli Yandara ${ }^{1}$, Khoidar Amirus ${ }^{2}$, Nurhalina Sari ${ }^{2}$ \\ ${ }^{1}$ Dinas Kesehatan Mesuji, Lampung, Indonesia \\ ${ }^{2}$ Fakultas Kesehatan Masyarakat Universitas Malahayati, Bandar Lampung, \\ Indonesia \\ *korespondensi Penulis: nurhalinasari@malahayati.ac.id
}

Penyerahan: 29-05-2020, Perbaikan: 23-08-2020, Diterima: 12-09-2020

\begin{abstract}
Based on the results of the Brabasan Puskesmas in January - December 2018, hypertension was ranked fifth (9.55\%), after Gastritis (11.58\%), and before Atrophic Dermatitis (5.64\%). The prevalence of hypertension in women at the Brabasan Community Health Center increased drastically in 2018 seen in the data for the last three years, namely 2016 (18.78\%), 2017 (13.79\%), 2018 (46.6\%). This study aimed to determine the factors related to hypertension in women in the work area of the Brabasan Public Health Center, Mesuji Regency, in 2019. This research is a quantitative study using a cross-sectional approach. The population was women in the work area of the Brabasan Community Health Center. They were aged 45 to 69 years, who were in Posbindu with a population of 600 people, a sample of 233 respondents using cluster sampling technique (Area Sampling) based on the Lemeshow formula-collecting data using a questionnaire and data analysis using the chi-square test. The results showed that the majority of hypertension was 131 respondents (56.2\%), most of the irregular exercise was 170 respondents (73.0\%), most of the light-moderate activities were 126 respondents $(54.1 \%)$, most of the stress was 130 respondents $(55.8 \%)$. There was no significant relationship between regular and irregular exercise with the incidence of hypertension $(p$-value $=0.143 ; O R=1.6)$. There was a relationship between physical activity and hypertension incidence with a value ( $p$-value $=<0.001 ; O R=4.3)$. there is a significant relationship between stress and the incidence of hypertension with an amount ( $p$-value $=0.037 ; O R=1.8$ ) with hypertension incidence. Suggestions for this research It is hoped that people can pay more attention to their lifestyle and health, including routine physical activities such as walking every day for 10 minutes and can activate themselves in every community activity to avoid stress.
\end{abstract}

Keywords: Hypertension, Exercise, Physical Activity, Stress.

\section{ABSTRAK}

Hipertensi adalah tekanan darah pengukuran mencapai $140 / 90 \mathrm{mmHg}$ atau lebih tinggi. Berdasarkan hasil Puskesmas Brabasan pada bulan Januari - Desember 2018 hipertensi menduduki peringkat kelima $(9,55 \%)$, sesudah Gastritis $(11,58 \%)$, dan sebelum Dermatitis Atropik (5,64\%). Prevalensi hipertensi pada perempuan di puskesmas brabasan meningkat drastis pada tahun 2018 terlihat pada data 3 tahun terakhir yaitu $2016(18,78 \%), 2017(13,79 \%), 2018$ (46,6\%).Tujuan penelitian ini untuk mengetahui tentang faktor yang berhubungan dengan hipertensi pada perempuan di wilayah kerja Puskesmas Brabasan Kabupaten Mesuji tahun 2019. Penelitian ini merupakan penelitian kuantitatif dengan menggunakan pendekatan cross sectional. Populasi adalah seluruh 
perempuan di wilayah kerja puskesmas brabasan yang berumur 45 tahun s/d 69 tahun yang berada posbindu dengan jumlah populasi 600 orang, sampel sejumlah 233 responden teknik pengambilan sampel dengan cara Cluster Sampling (Area Sampling) berdasarkan rumuslemeshow. Pengambilan data menggunakan kuesioner, dan analisa data menggunakan uji chi-square. Hasil penelitian menunjukan bahwa sebagian besar hipertensi 131 responden $(56,2 \%)$, sebagian besar olahraga tidak teratur 170 responden $(73,0 \%)$, sebagian besar aktifitas ringan-sedang 126 responden (54,1\%), sebagian besar stress 130 responden (55,8\%). Tidak ada hubungan yang signifikan antara olahraga teratur dan tidak teratur dengan kejadian hipertensi dengan nilai ( $p$-value $=$ $0,143 ; \mathrm{OR}=1,6)$, ada hubungan yang signifikan antara aktivitas fisik dengan kejadian hipertensi dengan nilai ( $p$-value $=<0,001 ; O R=4,3$ ), ada hubungan yang signifikan antara stress dengan kejadian hipertensi dengan nilai ( $p$-value $=0,037 ; \mathrm{OR}=1,8$ ), dengan kejadian hipertensi. Saran penelitian ini Diharapkan agar masyarakat dapat lebih memperhatikan gaya hidup dan kesehatannya, diantaranya adalah rutin melakukan kegiatan aktivitas fisik seperti berjalan kaki setiap hari selama 10 menit serta dapat mengaktifkan diri disetiap kegiatan kemasyarakatan agar terhindar dari stress.

Kata kunci: Hipertensi, Olahraga, Aktivitas fisik, Stress.

\section{PENDAHULUAN}

Hipertensi atau tekanan darah tinggi adalah kondisi kronis ketika tekanan darah pada dinding arteri (pembuluh darah bersih) meningkat. Kondisi ini dikenal sebagai "pembunuh diamdiam" karena jarang memiliki gejala yang jelas. Satu-satunya cara mengetahui bahwa seseorang memiliki hipertensi adalah dengan mengukur tekanan darah (Anies, 2018). Apabila tekanan darah 130 per 90 atau $130 / 90 \mathrm{mmHg}$, berarti anda memiliki tekanan sistolik 130 $\mathrm{mmHg}$ dan tekanan diastolik 90 $\mathrm{mmHg}$. Angka normal tekanan darah adalah yang berada pada 120/80 $\mathrm{mmHg}$. Seseorang akan dianggap mengidap hipertensi atau tekanan darah tinggi jika hasil dari beberapa kali pemerikasaan, tekanan darah tetap mencapai $140 / 90 \mathrm{mmHg}$ atau lebih tinggi (Anies, 2018).

Prevalensi hipertensi akan terus meningkat dan diprediksi pada tahun 2025 sebanyak 29\% orang dewasa diseluruh dunia terkena hipertensi. prevalensi hipertensi di indonesia sebesar $31,7 \%$ yang berarti 1 dari 3 orang mengalami hipertensi dan sebanyak 76,1\% tidak mengetahui dirinya telah mengalami hipertensi sehingga tidak mendapatkan pengobatan hipertensi. Padahal hipertensi yang tidak diobati dapat menyebabkan komplikasi yang fatal, seperti serangan jantung, stroke dan gagal ginjal. Hipertensi juga dapat menyebabkan kebutaan, irama jantung tak beraturan dan gagal jantung (Kemenkes RI, 2015).Perilaku kesehatan untuk memelihara dan meningkatkan kesehatan yang kondusif. Penyakit Perilaku kesehatan pada individu, kelompok, atau masyarakat dapat dirubah melalui promosi kesehatan/ Health Promotion (Notoatmodjo, 2012).

Terdapat dua faktor resiko pada penyakit hipertensi yaitu faktor yang tidak dapat diubah dan faktor yang dapat diubah. Faktor yang tidak dapat diubah adalah usia, jenis kelamin, dan keturunan (Genentik). Sedangkan faktor yang dapat diubah adalah obesitas, merokok, kurang aktivitas fisik, konsumsi garam berlebih, dislipidemia/kolesterol, konsumsi alkohol berlebih, psikososial dan stress (Kemenkes Ri, 
2014). Faktor-faktor resiko pada penyakit hipertensi yang tidak dapat diubah telah dilakukan penelitian dengan hasil sebagai berikut : Usia lansia yang terbanyak dalam penelitian ini yaitu kategori usia lansia (elderly) sebesar 82,5\%, sedangkan jenis kelamin sebagian besar subjek berjenis kelamin perempuan sebesar $80 \%$ (Novitaningtyas, 2014). Sedangkan penelitian tentang faktor resiko yang dapat diubah sebagai berikut : Menurut penelitian Alwin Imam (2014) ada hubungan yang signifikan antara olahraga dengan kejadian hipertensi dengan nilai $\mathrm{p}$ value $=0,039$ ( $p$-value $<0,05)$, serta dinilai OR yaitu 3,471. Hubungan antara merokok dengan kejadian hipertensi $(p=0,048>a=0,05 ; R P=1,477 ; 95 \%$ C1: 1,016-2,148) (Wahyuni, 2015). Prevalensi hipertensi di Indonesia berdasarkan hasil pengukuran pada penduduk umur $\geq 18$ tahun, pada tahun 2013 kejadian hipertensi sebesar $25.8 \%$ dan mengalami kenaikan pada tahun 2018 sebesar 34.1\% (Riskesdas, 2018).

Penyakit hipertensi di provinsi lampung menempati urutan ketiga dari 10 penyakit terbesar yaitu Influenza $(19,62 \%)$, Nasophringitis Akut $\quad(17,70 \%)$, Hipertensi $(16,18 \%)$, Gastritis $\quad(15,38 \%)$, Rheumatoid Atritis (10,32\%), Faringitis Akut $(5,03 \%)$, Diare dan Gastroenteritis $(4,73 \%)$, Febris $(4,71 \%)$, Mialgia (3,33\%), Darmatitis Atopik (3,02\%). ((Profil Dinas Kesehatan Provinsi Lampung, 2016). Pada tahun 2018 berdasarkan data dari 12 puskesmas tersebut penyakit hipertensi pada perempuan tertinggi persentasenya pada tahun 2018 adalah pada puskesmas Brabasan yang menduduki peringkat pertama yaitu dengan persentase Puskesmas Brabasan (12,24\%), Puskesmas Tri Karya Mulya $(11,24 \%)$, dan Puskesmas simpang pematang $(11,17 \%)$ (Profil Dinas Kesehatan Mesuji, 2018).

Menurut survey terpadu penyakit (STP) 10 penyakit besar di Puskesmas Brabasan pada bulan Januari - Desember 2018 hipertensi menduduki peringkat kelima $(9,55 \%)$, sesudah Gastritis $(11,58 \%)$, dan sebelum Dermatitis Atropik (5,64\%). Prevalensi hipertensi pada perempuan di puskesmas brabasan meningkat drastis pada tahun 2018 terlihat pada data 3 tahun terakhir yaitu $2016(18,78 \%), 2017$ (13,79\%), 2018 (46,6\%). (Profil Puskesmas Brabasan, 2018). Berdasarkan uraian-uraian diatas maka penulis tertarik untuk meneliti "Faktor Yang Berhubungan Dengan Hipertensi Pada Perempuan Di Wilayah Kerja Puskesmas Brabasan Kabupaten Mesuji Tahun 2019".

\section{METODE}

Penelitian ini merupakan penelitian kuantitatif dengan menggunakan pendekatan cross sectional. Populasi adalah seluruh perempuan di wilayah kerja puskesmas brabasan yang berumur 45 tahun s/d 69 tahun yang berada posbindu dengan jumlah populasi 600 orang, sampel sejumlah 233 responden teknik pengambilan sampel dengan cara Cluster Sampling (Area Sampling) berdasarkan rumuslemeshow. Pengambilan data menggunakan kuesioner, dan analisis data menggunakan uji chi-square. 
HASIL

Tabel 1. Distribusi Frekuensi Karakteristik Responden

\begin{tabular}{lcc}
\hline & Jumlah & Persentase (\%) \\
\hline $\begin{array}{l}\text { Kejadian Hipertensi } \\
\text { Hipertensi }\end{array}$ & 131 & 56,2 \\
$\quad \begin{array}{l}\text { Tidak Hipertensi } \\
\text { Olahraga }\end{array}$ & 102 & 43,8 \\
$\quad$ Olahraga tidak teratur & 170 & 73.0 \\
$\quad$ Olahraga teratur & 63 & 27.0 \\
Aktivitas Fisik & & \\
$\quad$ Berat & 107 & 45.9 \\
$\quad$ Ringan - Sedang & 126 & 54.1 \\
$\quad$ Stress & & \\
$\quad$ Stress & 130 & 55.8 \\
$\quad$ Tidak Stress & 103 & 44.2 \\
\hline
\end{tabular}

Tabel 2. Faktor Yang Berhubungan dengan Hipertensi

\begin{tabular}{llllc}
\hline \multirow{2}{*}{ Variabel } & \multicolumn{2}{c}{ Kejadian Hipertensi } & \multicolumn{1}{c}{$\begin{array}{c}\text { P- } \\
\text { value }\end{array}$} & $\begin{array}{c}\text { OR } \\
\text { (CI95\%) }\end{array}$ \\
\cline { 2 - 3 } $\begin{array}{l}\text { Olahraga } \\
\text { Olahraga tidak teratur }\end{array}$ & $101(59.4 \%)$ & $69(40.6 \%)$ & 0.143 & $\begin{array}{c}1,6 \\
\text { Olahraga teratur }\end{array}$ \\
$\begin{array}{l}\text { Aktivitas Fisik } \\
\text { Berat }\end{array}$ & $30(47.6 \%)$ & $33(52.4 \%)$ & & \\
$\begin{array}{l}\text { Ringan - Sedang } \\
\text { Stress }\end{array}$ & $80(74.8 \%)$ & $27(25.2 \%)$ & $<0,001$ & 4.3 \\
Stress & $51(40.5 \%)$ & $75(59.5 \%)$ & & $(2.4-7.6)$ \\
Tidak Stress & $82(63.1 \%)$ & $48(36.9 \%)$ & 0.037 & 1.8 \\
\hline
\end{tabular}

Hasil uji statistik didapat p-value 0.143 yang berarti bahwa tidak ada hubungan yang signifikan antara olahraga dengan kejadian hipertensi. Dengan nilai $\mathrm{OR}=1.6$ yang berarti bahwa responden yang tidak olahraga teratur tidak mempunyai faktor resiko menderita hipertensi dibandingkan dengan responden yang olahraga teratur.

Hasil uji statistik didapat p-value $<0.001$ yang berarti bahwa ada hubungan yang signifikan antara aktivitas fisik dengan kejadian hipertensi. Dengan nilai $\mathrm{OR}=4.3$ yang berarti bahwa responden yang

\section{PEMBAHASAN}

Hasil penelitian ini tidak sejalan dengan penelitian Ainul Hiroh (2012) Dengan judul faktor-faktor yang berhubungan dengan aktivitas fisik berat mempunyai faktor resiko sebanyak 4 kali lebih besar untuk menderita hipertensi dibandingkan dengan responden yang aktivitas ringan-sedang.

Dari hasil penelitian menunjukkan bahwa dari 130 responden yang stress terdapat 82 responden (63.1\%) yang menderita hipertensi. Hasil penelitian ini sejalan dengan hasil penelitian Mustamiatul Khairiah (2019) yang menyebutkan bahwa ada hubungan antara tingkat stres dengan tingkat kekambuhan pada penderita hipertensi.

terjadinya hipertensi pada .pasien rawat jalan di RSUD Kabupaten Karanganyar yang menunjukan bahwa ada hubungan yang bermakna antara kebiasaan olahraga dengan kejadian hipertensi dan 
responden yang tidk teratur hipertensi dibandingkan responden yang mempunyai kebiasaan olahraga teratur. Menurut teori Kemenkes RI (2014) Olahraga adalah salah satu bentuk aktivitas fisik yang dilakukan secara terstruktur, terencana dan berkesinambugan dengan mengikuti aturan-aturan tertentu dan bertujuaan untuk meningkatkan kebugaran jasmani dan prestasi. Yang termasuk dalam olahraga permainan seperti sepak bola, bulu tangkis, basket, berenang, dan sebagainya. Dari hasil data yang didapat banyak nya responden yang menjawab jenis olahraga seperti jalan kaki, jogging, senam karna kurang jelas nya pertanyaan dikuisioner olahraga yang dibuat peneliti yang memungkinkan responden menjawab pertanyaan tersebut tidak tepat karna jalan kaki dan jogging, senam itu masuk ke aktifitas bagian latihan fisik. Kurang tepatnya jawaban yang disediakan peneliti. Jawaban yang seharusnya spesifik ke bagian olahraga permainan. Kurang jelasnya instrumen pertanyaan pada kuisioner variabel olahraga yang memungkinkan hasil penelitian menjadi tidak berhubungan, jika dijelaskan secara spesifik olahraga permainan apa yang sering dilakukan responden secara terarur perminggunya kemungkinan bisa saja hasil penelitian tersebut menjadi berhubungan antara olahraga dengan kejadian hipertensi. Menurut pendapat peneliti meskipun responden tidak olahraga teratur namun aktifitas fisik nya teratur cenderung tidak hipertensi hal tersebut dikarenakan telah melakukan pergerakan pada latihan seperti senam yang dilakukan pada aktifitas fisik. olahraga permainan olahraga berisiko 3.33 kali terkena seperti bulu tangkis, renang, tenis meja dan lain sebagainya disarankan untuk usia pra lansia. Untuk umur diatas 60 tahun atau lansia disarankan untuk olahraga kelatihan fisik saja seperti senam teratur minimal 20-30 menit semiggu.

Hal ini sesuai dengan teori dari Kemenkes RI (2014) Kegiatan sehari-hari dalam membersihkan rumah bisa membantu Anda untuk membakar kalori yang didapatkan dari makanan yang dikonsumsi. Seperti misalnya adalah mencuci baju, mengepel, jalan kaki, membersihkan jendela, berkebun, menyetrika, bermain dengan anak, dan sebagainya. Kalori yang terbakar bisa 50 - $200 \mathrm{kcal}$ per kegiatan. Aktifitas fisik dapat dinilai dari aktifitas ditempat kerja, aktifitas berat dipegaruhi dari kegiatan yang lebih banyak diluar ruangan dan banyak bergerak seperti atletik, tentara dan buruh. Aktifitas ini dilakukan lebih dari 3 hari dalam seminggu dan lebih dari 4 jam dalam seminggu. Aktifitas sedang dipengaruhi dari kegiatan yang dilakukan baik didalam maupun di luar ruangan, eseorang kurang aktif secara fisik (yang aktifitas fisiknya urang dari 3 kali seminggu atau kurang perminggu 30 menit) memiliki hampir $50 \%$ resiko terkena stroke dibanding mereka yang aktif beraktifitas fisik. Berbagai kemudhan hidup yang didapat seperti mencuci dengan mesin cuci untuk rumah tangga, banyanya kendaraan bermotor serta kemajuan teknologi membuat aktifitas seseorang semakin hari semakin ringan atau mudah. Namun dampak dari kemajuan teknlogi ini seseorang dapat menjadi pasif dan cenderung menimbulkan sedikit nya beraktifitas 
fisik dan dapat meningkatkan resiko terjadinya hipertensi yang nantinya memicu terjadi kaku terhadap otototot tubuh jika tidak diimbangi dengan aktifitas fisik yang cukup (Wahyu, 2009). Berdasarkan tabel hasil penelitian menunjukan bahwa responden banyak yang melakukn aktifitas fisik ringan-sedang 51 responden $(40.5 \%)$ yang menderita hipertensi dan 75 responden (59.5\%) tidak hipertensi, sedangkan dari 107 responden yang aktifitas fisik berat terdapat 80 responden (74.8\%) yang mnderita hipertensi dan 27responden (25.2\%) yang tidak menderita hipertensi. Hal ini sejalan dengan jurnal yang diteliti oleh Karim (2018) menyatakan dari hasil peneelitiannya sebanyak $70 \%$ responden yang melakukan aktifitas sedang seperti mencuci pakaian, menyapu, mencuci piring, menyetrika, memasak dan sebanyak $30 \%$ responden yang melakukan aktifitas fisik berat seperti menimba air, mencangkul dan menebang pohon. Aktifitas ringan tergantung pada jenis kegiatan, intensitas dalam sehari, durasi dan frekuensi kegiatan.

Menurut penelitian responden yang melakukan aktifitas berat cenderung lebih beresiko terkena hipertensi. Jadi aktifitas fisik responden mempengaruhi terjadinya hipertensi, dari penemuan penelitian ini bahwa aktifitas fisik berat di dominasi usia lanjut padahal seharusnya usia lanjut tidak banyak melakukan aktifitas fisik berat. Agar tidak berpengaruh terjadinya hipertensi seseorang diharapkan untuk melakukan aktifitas ringan sedang secara rutin untuk usia 18-64 tahun wajib memenuhi kebutuhan aktifitas fisik yaitu 150-300 menit aktifitas sedang atau 75 menit aktifitas fisik berat dalam seminggu, latihan otot kerangka sebanyak 3-4 kali dalam seminggu.

Hal ini sesuai dengan teori Muhammadun As (2010) stress atau ketegangan jiwa adalah rasa tertekan, murung, rasa marah, dendam, rasa takut rasa bersalah. Dapat merangsang anak ginjal melepaskan hormoneadrenalin dan memacu jantung berdenyut lebih cepat dan kuat, sehingga tekanan darah meningkat. Jika stress berlangsung lama, tubuh akan berusaha mengadakan penyesuaian sehingga timbul kelainan organis atau perubahan patologis, gejala yang memucul dapat berupa hipertensi. Dari 103 responden yang tidak stress terdapat 49 responden $(47.6 \%)$ yang menderita hipertensi, hal ini disebabkan oleh responden mempunyai faktor resiko lainnya seperti: pekerjaan, tanggung jawab, pengambilan keputusan, tempat tinggal, hubungan pribadi, keuangan, dan kesehatan yang menimbulkan respon tubuh yang sifatnya non spesifik terhadap setiap tuntunan beban atas yang dialami seseorang yaang menyebabkan peningkatan tekanan darah. Berdasarkan analisa data menunjukkan bahwa bahwa dari 130 responden yang stress terdapat 82 responden $(63.1 \%)$ yang menderita hipertensi dan 48 responden (36.9\%) tidak menderita hipertensi, sedangkan dari 103 responden yang tidak stress terdapat 49 responden (47.6\%) yang menderita hipertensi dan 54 responden (52.4\%) yang tidak menderita hipertensi. Hasil uji statistik didapat $p$-value 0.037 yang berarti bahwa ada hubungan yang signifikan antara stress dengan kejadian hipertensi di wilayah kerja puskesmas Brabasan tahun 2019. Kemudian didapat nilai $\mathrm{OR}=1,8$ yang berarti bahwa responden yang 
stress mempunyai faktor resiko sebanyak 1,8 kali lebih besar untuk menderita hipertensi dibandingkan dengan responden yang tidak stress. Menurut pendapat peneliti salah satu cara untuk menghindari stress yaitu dengan membuat suasana yang menenangkan dan melakukan relaksasi rutin setiap hari. Hal ini penting dilakukan karna memberikan efek ketenangan yang dapat mengontrol sistem syaraf sehingga dapat menurunkan tekanan darah. Stress yang terjadi di wilayah kerja puskesmas brabasan didominasi dengan banyaknya jumlah anak pada responden dan sosial ekonomi/keuangan yang kurang. Hal ini dikarenakan harga hasil perkebunan yang relatif murah yang diberikan untuk masyarakat dari pemerintah. Contoh nya harga karet, sawit dan singkong. Mayoritas masyarakat wilayah kerja puskesmas brabasan pekerjaannya sebagai buruh perkebunan dan banyak yang menjadi IRT (ibu rumah tangga) saja. Serta jumlah anak rata-rata lebih dari 2 anak yang membuat kebutuhan lebih banyak dibandingkan penghasilan. Stress yang dialami seseorang akan membangkitkan saraf simpatetis yang akan memicu kerja jantung dan menyebabkan peningkatan tekanan darah. Oleh karena itu bagi mereka yang sudah memiiki riwayat hipertensi, disarankan untuk berlatih mengendalikan stress dalam hidupnya. Stress tidak hanya memicu timbulnya hipertensi, tetapi juga banyak penyakit fisik berat lainnya yang disebabkan oleh stress. Hidup sehat dan menggunakan pola pikir sehat merupakan salah satu cara untuk mengendalikan stress.
Tidak ada hubungan yang signifikan antara olahraga dengan kejadian hipertensi. Terdapat antara aktivitas fisik dan stress dengan kejadian hipertensi.

\section{SARAN}

Mendukung upaya yang dilakukan responden, dalam mempertahankan derajat kesehatannya dengan memotivasi responden saat melakukan kontrol kesehatan dan melakukan aktifitas fisik dirumah seperti berjalan setiap hari selama 10 menit. Memberikan informasi kepada responden faktor yang mempengaruhi kejadian hipertensi khususnya lebih meningkatkan kegiatan aktifitas fisik sehari-hari seperti contohnya membersihkan rumah yaitu mencuci baju, jalan kaki, menyapu, berkebun dan lainlain bertujuan untuk dapat meningkatkan pengeluaran tenaga atau energi. Memberikan informasi kepada responden untuk melakukan kegiatan yang menyenangkan dan melakukan hal-hal yang bermanfaat dalam hidup agar tidak merasa bosan, memiliki semangat yang baik dalam menjalani hidup dalam hal tersebut bertujuan agar terhindar dari stress.

\section{DAFTAR PUSTAKA}

Anies, A. (2018). Penyakit Degeneratif.

Dinas kesehatan Kabupaten Mesuji, (2018). Profil Dinas Kesehatan Kabupaten Mesuji, Tahun 2018.

Dinas kesehatan Provinsi Lampung, (2016). Profil Dinas Kesehatan Provinsi Lampung, Tahun 2016 Kemenkes RI, (2014). Pengukuran Faktor Risiko PTM Seri 3, Kemenkes RI. Jakarta

\section{KESIMPULAN}


Kemenkes RI, (2014). Penyakit Tidak Menular Dan Faktor Risiko Sesi 2, Kemenkes Ri. Jakarta

Kemenkes RI, (2014). Upaya Pengendalian Faktor Risiko PTM Sesi 4, Kemenkes Ri. Jakarta

Kemenkes RI, (2018). Hasil Utama Riskesdas 2018. Indonesia; Kementerian Kesehatan Badan Penelitian dan Pengembangan Kesehatan

Muhammadun, A. S. (2010). Hidup Bersama Hipertensi. Jogjakarta.

Muliyati, H., Syam, A., \& Sirajuddin, S. (2011). Hubungan pola konsumsi natrium dan kalium serta aktifitas fisik dengan kejadian hipertensi pada pasien rawat jalan di RSUP dr. Wahidin Sudirohusodo Makassar. Media GiziMasyarakat Indonesia, 1(1), 46-51. Diakses 23 agutus 2019.

Notoatmodjo, S. (2012). Promosi Kesehatan dan Perilaku Kesehatan, Jakarta: Rineka Cipta. Prince, SA (2005). Patofisiologi: Konsep klinis proses-proses penyakit.

Novitaningtyas, T. (2014). Hubungan karakteristik (umur, jenis kelamin, tingkat pendidikan) dan aktivitas fisik dengan tekanan darah pada lansia di Kelurahan Makamhaji Kecamatan Kartasura Kabupaten Sukoharjo (Doctoral dissertation, Universitas Muhammadiyah Surakarta).

Wahyu R. 2009, Hipertensi Pada Pelayanan Kesehatan Primer

Diambildarihttp://scholar.google. com/scholar?q= wirawan $+r+$ prad anasari+hi

pertensi+pada+pelayanan+keseh atan + primer\&btnG $=\& \mathrm{hl}=$ en\&as $\mathrm{sdt}=0 \% 2 \mathrm{c5}$ Diakses pada tanggal 27 November 2019
Wahyuningsih, D. (2015). Hubungan Antara Perilaku Olahraga Dan Merokok Dengan Kejadian Hipertensi Di Wilayah Kerja Puskesmas Kartasura Kabupaten Sukoharjo (Doctoral dissertation, Universitas Muhammadiyah Surakarta). Kesmas, 6(4). 